\title{
A TECTÔNICA DE JEAN NOUVEL
}

Mariana Faccin, Rafael Foltran, Beatriz Minatti, Claudia Sawada, Korina Aparecida Teixeira Ferreira da Costa

Universidade do Oeste Paulista - UNOESTE, Curso de Arquitetura e Urbanismo, Presidente Prudente, SP. E-mail: korina.arq@gmail.com

\section{RESUMO}

O objetivo deste estudo é apresentar a tectônica de Jean Nouvel através da abordagem de algumas obras do arquiteto, definindo essa tectônica por meio de um levantamento bibliográfico e documental de três importantes obras do arquiteto, com um estudo mais aprofundado, mostrando a linguagem de sua arquitetura e de sua tectônica, revelando que podem ser de lugares diferentes e distintas entre si, mesmo fazendo a utilização de materiais iguais. Com as análises das obras pode-se notar que o arquiteto une seus projetos à uma consciência ecológica, que se torna uma de suas principais vertentes, o high-tech, como uma de suas linhas de pensamento.

Palavras-chave: Jean Nouvel, Tectônica, Consciência ecológica, High-Tech, Eco-tech

\section{THE TECTONICS OF JEAN NOUVEL}

\section{ABSTRACT}

The objective of this study is to present the tectonic Jean Nouvel through some works of the architect approach, setting this tectonic through a bibliographic and documentary survey of three important works of architect, with further study, showing the language of yours and a tectonic, revealing that may be of different locations and different from each other, even by making use of the same materials. With the analysis of the works may be noted that the architect joins their projects to an ecological conscience, which becomes one of its main aspects, the high-tech, as one of its lines of thought.

Keywords: Jean Nouvel, Tectonics, Environmental awareness, High-Tech, Eco-Tech 


\section{INTRODUÇÃO}

A arquitetura High-Techsurgiu na década de 1970, tendo sido um dos movimentos mais expressivos do modernismo tardio.Enfatiza a tecnologia e a tectônica, geralmente aplicada naestrutura do edifício, tratada como um ornamento. Este movimento teve como base a arquitetura moderna, utilizando-se de elementos técnicos como uma espécie de pastiche, especialmente quando colocados juntos, e em sequência repetitiva.

Kate Nesbitt cita em seu livro que nas décadas de 50 e 60, o ornamento era chamado de detalhe e era tratado como algo mínimo e sua arte partia da união de materiais e elementos que compunham a construção de maneira que fosse estético e funcional. A arquitetura não era apenas profissão, era tratada como arte. (NESBITT, 2008)

[...] é importante reafirmar que a arquitetura é tanto uma arte como uma profissão [...] arte porque se ocupa não so da necessidade primordial do abrigo, mas também da uniao de espaços e materiais de uma maneira significativa. (NESBITT, 2008, p. 552)

As principais características da Arquitetura High Tech são uso do aço e vidro, interiores flexíveis, cor utilizada nas tubagens, serviços, materiais leves e concentração de circunferências verticais e prumadas.

Pode-se observar no Arquitetura do Novo Milênio alguns exemplos destavertente arquitetônica, tais como: Câmara municipal em Londres, Torre Eiffel e do Centro Georges Pompidou em Paris, HSBC sede em Hong Kong, Hotel Arts Skidmore, a Torre Agbar, em Barcelona, e o Centro Nacional de Artes Performáticas, em Pequim. (BENÉVOLO, 2007)

Ainda tendo como base Benévolo, nos são apresentados notáveis representantes da arquitetura high-tech comoNorman Foster, Renzo Piano, Richard Rogers,Jean Nouvel, Michael Hopkins, Schweger \& Partner, Paul Andreu, e Michel Virlogeux.

Benévolo fala sobre as tectônicas, onde Norman Fosterse destaca pela forma das edificações, uso do aço, coberturas arredondadase utilização de cúpulas e muito vidro. Também diz sobre Richard Rogers onde a sua parte do uso de estrutura metálica aparente, e sua referência é a fábrica, em termos de estrutura metálica e no sentido do não acabado, algo que se encontra em constante evolução.Sobre Renzo Piano a utilizaçãode paredes envidraçadas internas e externas, utilizando também formatos orgânicos. Nas edificações mais horizontais a linha orgânica aparece geralmente na cobertura, diferente das torres que apresenta, por vezes, o formato de cone. (BENÉVOLO, 2007). 


\section{METODOLOGIA}

A metodologia basea-se numa investigação bibliográfica e se fundamentará numa abordagem qualitativa de pesquisa, utilizando-se como instrumento um levantamento bibliográfico e documental, que segundo Teixeira (2000, p. 137), busca a correlação entre a teoria e os dados, entre o contexto e a ação, a partir da compreensão dos fenômenos por meio de sua descrição e interpretação. Para o trabalho com o estudo do tipo de levantamento bibliográfico ocorrerá inicialmente um levantamento das principais produções no contexto nacional de estudos, considerando a peculiaridade do objeto de estudo.

Desse modo, percebe-se que a pesquisa qualitativa vale-se do método indutivo, segundo o qual parte da observação, da análise dos fatos particulares, dos registros para compor um quadro compreensivo para então constituir a generalização universal, ou seja, a teoria. O processo de indução vale-se do princípio do empirismo, no qual o conhecer é dar significado à realidade (KÖCHE, 1997, p. 62).

\section{JEAN NOUVEL}

Nascido em Fumel - França, no ano de 1945, Jean Nouvel foi admitido na Ecole Nationale Supérieure des Beaux Arts em Paris, no ano de 1966. Durante a faculdade foi assitente de Claude Parent e Paul Virilio. Formou-se em 1972, e no mesmo ano associou-se à François Seigneur e Gilbert Lézénès. Co-fundador do movimento arquitetônico francês "Mars 1976", e da Bienal de Arquitetura de Paris, fundou em 1984 o Jean Nouvel et Associés, e em 1994 estabeleceu o Ateliers Jean Nouvel. (NOUVEL, Jean , 2015-a)

A extensão do Museu Nacional Centro de Arte Reina Sofia (2001-2005), foi conduzida por Jean Nouvel e é composta por 3 blocos, que formam um triângulo truncado,e apresenta um pátio central. Construído em concreto armado, contempla tanto formas retas quanto curvas, de acentuada inclinação, como as duas costelas estruturais que compõem os auditórios.

Esta obra apresenta uma cobertura caricata, com $8.000 \mathrm{~m}^{2}$, elevada 6 metros sobre os terraços dos edifícios com a face voltada ao solo de cor vermelha, o que instiga a atenção do público que a observa.

A extensão respeita a representatividade do antigo edifício, seguindo o gabarito de altura, preservando algumas paredes para afirmar o sentido de mutação e extendendo a pedra pedestal do existente para toda a nova área do museu. 
Localizado em Madrid, na Espanha, com $26.892 \mathrm{~m}^{2}$ atende dois espaços de exposições temporárias, auditório com 500 lugares, biblioteca, cafeteria, restaurante, escritórios de administração. (PROJECT, Art, 2015; NOUVEL Jean, 2015-b)

Também na Espanha, porém em Barcelona, em um dos principais centros de circulação e distribuição de fluxo da cidade, localiza-se a Torre Agbar, de Nouvel, inspirada nas montanhas de Montserrat e nas torres da Sagrada Família, o terceiro edifício mais alto da cidade, apresenta aproximados 142 metros de altura, e teve sua conclusão em Julho de 2005.

Seus $50.500 \mathrm{~m}^{2}$ construídos estão distribuídos em 38 pavimentos -28 destinados à oficinas e escritórios; 3 destinados à centralização das instalações; 1 pavimento para cafeteria, salas polivalentes e mirante da cúpula da torre; 4 pavimentos subterrâneos, onde 2 se destinam ao auditório com capacidade para 316 pessoas (mais serviços), e os outros 2 ao estacionamento.

De planta constituída por dois elementos cilíndricos - central e externo, este edifício tem sua estrutura composta exclusivamente por concreto armado até o 26 ㅇ andar, e nos andares posteriores composto por concreto armado (estrutura central) e vidro e metal (estrutura externa de vedamento).

Sua representatividade e beleza é dada por suas 3 "peles", a primeira -estrutural- de concreto armado, possui 4.500 aberturas distribuídas desuniformemente, que maximiza a incidência solar, reduzindo gastos energéticos. A segunda -pastiches/decorativo- é composta por placas de alumínio nas cores vermelho, azul e cinza, distintas em 40 tons. E a terceira -vedaçãocomposta por fitas de vidro, reguladas através de sensores climáticos, a fim de reduzir a necessidade do funcionamento do ar condicionado, permitindo uma ventilação natural, voltado também à uma consciência energética.(FUNDAÇÃO, Agbar, 2015; NOUVEL, Jean, 2015-c; LAYETANA, Inmobiliaria, 2008)

Com a evolução tecnológica e dos meios construtivos, e a crescente preocupação com a relação da obra e o meio ambiente uma nova vertente arquitetônica veio surgindo, o Eco Tech, que emprega muita tecnologia para estabelecer a maior interatividade da obra com o meio que o circunda, e com a natureza e seus recursos.

Acompanhando este movimento, Nouvel projetou o One Central Park, para um dos blocos do Frasers Broadway, em Sydney. Composto por duas torres, apresentando 34 e 12 andares, contendo apartamentos residenciais, escritórios e serviços diversos.

Elaboradas em colaboração com o botânico e artista francês Patrick Blanc, as fachadas apresentam vegetação que cobrem $50 \%$ de sua extensão, verticalizando a paisagem, que se 
estende do parque urbano adjacente sobre o edifício, criando um ambiente de vida excepcional para os residentes do edifício e um ícone verde e poderoso no skyline Sidney.

As plantas funcionam como um dispositivo de controle solar natural que muda com as estações do ano, protegendo os apartamentos de sol direto durante o verão enquanto admite a incidencia solar máxima no inverno.

Graças à combinação de estratégias de design sustentável, o edifício foi o primeiro residencial em Sidney a receber classificação de 6 'estrelas verdes'.

Os apartamentos e escritórios apresentam galerias internas e externas ampliando o espaço de relação com a vegetação e aproveitando ao máximo o clima da cidade. Estas galerias ainda servem para proteger os residentes de ruídos externos e direcionar a vista para o parque adjacente.

A maior torre é marcada por um cantilever monumental perto de seu cume, que abriga um terraço panorâmico e um helioxtato motorizado, que capta e reflete a luz solar para a área central entre as torres.

A torre e o parque se ligam através de terraços escalonados em cascata, que abrigam cafés, lojas e uma praça que fornecem acesso ao centro comercial do complexo tornando o passeio fluido.( PROPERTY, Frasers, 2013; NOUVEL, Jean, 2015-d)

Este projeto de Nouvel impulsionou a integração entre o edifício e a paisagem em um nível tão intenso que proporcionou à Sidney um novo ícone arquitetônico, simbolizando o futuro sustentável da cidade, ao receber o título de melhor edifício de 2014 pelo Conselho de Grandes Construções e Habitat Urbano (CTBUH). (HABITAT, Council On Tall Buildings And Urban, 2014).

\section{CONSIDERAÇÕES FINAIS}

Observamos que nas obras citadas de Jean Nouvel, sua visão de tectônica está ligada às membranas do edifício, ou seja, no detalhamento de suas diversas camadas. Na primeira obra, o Museu de Arte Reina Sofia, a tectônica se encontra nas formas curvas das paredes de concreto, na cobertura suspensa e colorida, apresentando claraboias em forma de cúpula suspensa, e nas venezianas de aço perfuradas em padrões caligráficos. Já a Torre Agbar, as membranas se dão em três superfícies variadas em concreto, aço e vidro, dando uma textura diferenciada na aparência do prédio, como se fossem três camadas de pele sobrepostas - na sequência : estrutural-pastichevedação. No One Central Park as membrana que se destacam são as formas extendidas das sacadas e suas vedações, que proporcionam interação interno/externo e que é complementada pelo uso da vegetação vertical, que causa a sensação de que a natureza envolve o edifício. 
Através dessa análise chega-se a conclusão de que a palavra tectônica pode ser interpretada de diversas maneiras. Jean Nouvel a interpreta como os detalhes que envolvem a obra, as "membranas" do edifício, já outros arquitetos podem interpretar a tectônica de outras formas, cada um com sua característica específica. Podemos comparar a tectônica com um poema, onde cada indivíduo pode interpretar e sentir de um modo diferente, dando diversos significados a uma mesma obra.

\section{REFERÊNCIAS BIBLIOGRÁFICAS}

AMRUTIA, Jay. Hightech Arquitetura Estilo: Arquitetura Sustentável ou Eco-tech Style Design. Publicado em: 20/02/2015. Disponível em: http://kadvacorp.com/design/hightech-architecturestyle/ . Acessado em Março de 2015.

BENÉVOLO, Leonardo.Arquitetura do novo milênio.2007.

FUNDACIÓN, Agbar. Torre Agbar. Publicado em: 2015. Disponível em: http://www.torreagbar.com/home.asp . Acessado em Março de 2015.

HABITAT, Council On Tall Buildings And Urban. CTBUH Names One CentralPark "Best Tall Building Worldwide" for 2014.Publicado em: 06/11/2014. Disponível em: http://www.ctbuh.org/Awards/AllPastWinners/2014Awards/AwardsDinner/tabid/6642/language/ en-US/Default.aspx . Acessado em Março de 2015.

KÖCHE, J. C. Fundamentos de metodologia científica: teoria da ciência e iniciação à pesquisa. 22 . ed. São Paulo: Vozes, 2004.

LAYETANA, Inmobiliaria. Torre Agbar: "La torre que toca el cielo". Publicado em: 04/11/2008. Disponível em: https://www.youtube.com/watch?v=L5xbaMjLYbc. Acessado em Março de 2015. NESBITT, Kate.Uma nova agenda para a arquitetura: Antologia Teórica. 2.Ed., 2008.

NOUVEL, Jean. Biografia. Publicado em: 2015 (2015-a). Disponível em: http://www.jeannouvel.com/en/desktop/home/\#biographie. Acessado em Março de 2015.

NOUVEL, Jean. Museu Reina Sofia. Publicado em: 2015 (2015-b). Disponível em: http://www.jeannouvel.com/en/desktop/home/\#/en/desktop/projet/madrid-spain-reina-sofiamuseum1. Acessado em Março de 2015.

NOUVEL, Jean. Torre Agbar. Publicado em: 2015 (2015-c). Disponível em:http://www.jeannouvel.com/en/desktop/home/\#/en/desktop/projet/barcelona-spain-torreagbar1. Acessado em Março de 2015.

NOUVEL, Jean. Central Park Sidney. Publicado em: 2015 (2015-d). Disponível em: http://www.jeannouvel.com/en/desktop/home/\#/en/desktop/projet/sydney-ocp . Acessado em Março de 2015. 
PROJECT, Art. Museu Reina Sofia. Publicado em: 2015. Disponível em: http://www.museoreinasofia.es/en/museum/history . Acessado em Março de 2015.

PROPERTY, Frasers. Central Park Sidney. Publicado em: 2013. Disponível em: http://www.centralparksydney.com/live/one-central-park\# . Acessado em Março de 2015.

TEIXEIRA, E. As três metodologias. 2ạ.ed. São Paulo: Vozes, 2000. 